\title{
Antropología del cuerpo y el dolor
}

\section{Anthropology of the body and pain}

\author{
Manuel Enrique Muñoz Mainato ${ }^{1}$ \\ Nazareno73_mm@hotmail.com
}

\begin{abstract}
Resumen
El culto al cuerpo está presente en todas las culturas y épocas históricas, así como "la experiencia del dolor" que ha conducido a los seres humanos al ejercicio del dominio y del poder de unos sobre otros mediante la aplicación de dolor sobre los cuerpos; verbigracia el dominio ideológico de tinte religioso ejercido por los patriarcas hebreos, los cultos sumerios, mesopotámicos, egipcios, griegos, romanos, aztecas, mayas, incas, etc. Durante el Medievo se constató esta realidad con más claridad. Un cuerpo torturado, sometido al dolor y al suplicio no es sino un referente pedagógico para sus congéneres. El miedo, el terror son patrones que diseñan un tipo de conducta humana, hacen de los seres humanos unos instrumentos de utilidad de los poderosos, de los delincuentes, de los narcotraficantes cuyo único propósito es acrecentar su imperio del capital por el poder de las armas.
\end{abstract}

\section{Palabras clave}

Experiencia, cuerpo, dolor, poder, dominio, mercado.

\begin{abstract}
The cult to the body is present in all the cultures and epochs historical, as well as "the experience of the pain" that has led the human beings to the exercise of the domain and of the power of some over others by means of the pain application on the bodies; for example the ideological mastery of religious dye exercised by the Hebrew patriarchs, the educated Sumerian, Mesopotamian, Egyptian, Greek, Roman, Aztec, Mayan, Inca, etc. During the Middle Ages, this one was stated realize with more clarity. A body tortured, submitted to the pain and to the torture is not but a pedagogic modality for its congeners. The fear, the terror are bosses who design a type of human conduct, they do of the human beings a few instruments of utility of the powerful ones, of the delinquents, of the drug traffickers whose only intention is to increase its empire of the capital for the power of the weapon.
\end{abstract}

\section{Keywords}

Experience, body, pain, power, domain, market.

Forma sugerida de citar: Muñoz Mainato, Manuel Enrique (2016). Antropología del cuerpo y el dolor. Universitas, XIV(24), pp. 41-62.

1 Candidato PhD en Antropología. 


\section{Introducción}

El cuerpo y el dolor son temas recurrentes en todos los espacios y culturas, de forma particular se ha observado en el austro ecuatoriano, donde el lenguaje corporal resulta vital en el proceso de la construcción socio-cultural, en la consolidación de las relaciones filiales. Para ello ha sido necesario elaborar un marco teórico referente al cuerpo y su contexto histórico-cultural, resaltando la experiencia del dolor que el ser humano ha experimentado en su proceso evolutivo, en diferentes épocas históricas. También se analizan conceptos tales como la tortura, el suplicio y el heroísmo como formas sociales que han dado paso a una cultura del dolor y el sacrificio. Hay que resaltar que el cuerpo ha sido objeto de cognición y manipulación en diversos escenarios históricos tanto en su estado saludable, enfermizo como mercantil, cerrando el estudio con una reflexión sobre lo inexpugnable que resulta la conquista del cuerpo como tal para el ser humano actual.

La investigación pretende una lectura reflexivo-crítica de la relación del hombre con su cuerpo y las formas y manifestaciones socioculturales en torno al mismo, para abrir un debate social que posibilite una comprensión de la violencia generalizada en el hombre del siglo XXI, entendiendo la dimensión de la violencia ejercida por agrupaciones delictivas, narcotraficantes, grupos reaccionarios, paramilitares, guerrillas, sicariato, etc.

Una cultura del dolor, del sufrimiento se puede representar en la frase lapidaria: ¡Resignación! Acuñada por todos y cada uno de los procesos de colonización en la mentalidad del indio. De alguna manera el pobre siente el sufrimiento y el dolor corporal como una forma de vida típica de su condición; es indigno de una vida armónica, saludable y feliz. Por otro lado, se ha generado una cultura de culto al cuerpo desmedido, en torno al cual se ha desarrollado con sofisticada precisión un mercado exitoso de los fármacos y los cosméticos. También el dolor experimentado en el cuerpo humano, por las enfermedades y la violencia o la necesidad de un reconocimiento social del individuo también ha dado paso a un complejo mundo del mercado y el negocio.

Los procesos propios de la evolución humana, harán que los niveles de consciencia cada vez más sutiles liberen a las personas de las esclavitudes contemporáneas. 


\section{Contexto histórico cultural del culto al cuerpo}

El ser humano desde antaño, en las cuevas, tiendas de campaña o edificaciones sofisticadas, sepulcros (egipcios, griegos, romanos, aztecas, mayas, chibchas, incas, nazcas, cañaris -sidumas-, etc.), ha dejado indicios evidentes del culto, de las formas y estilos de manipulación del cuerpo en diferentes estados: dolor, enfermedad, belleza, fealdad, obesidad, anorexia, status social, etc. A los incas, verbigracia, los colonos españoles los apodaron "orejones" por lo prolongado de la campana auditiva, debido a las incrustaciones, ya sea de aros de oro o de madera, cuyo significado evocaba la nobleza y la estirpe (González Suárez, 1989). Los cañaris -"siduma" =dominio de la luna=los que adoraban la luna- (Burgos Guevara, 2003, p. 14), según documentos de Ciesa de León, mencionado por Burgos en su mismo artículo, afirma que tenían por costumbre llevar cabello largo y trenzado, sobre su cabeza colocaban una madera circular de tres dedos de ancho, a la manera de una corona; en ausencia de la madera, usaban una calabaza, por lo que a los siduma se les calificaba de matihuma (cabeza de calabaza). Tenían también por costumbre envolver a los recién nacidos con trozos de frazadas tejidas de lana, ajustándolos con fajas. A este trabajo lo llaman el maitu, la envoltura.

\section{La persona y "la experiencia del dolor"}

Con seguridad, todos los actos relacionados con la manipulación y alteración de la normal presentación del cuerpo humano producían un dolor, tolerable, según la costumbre de la cultura. Por tal motivo en este artículo se adopta el término "experiencia del dolor" (Torres, M., \& Compañ, V., 2006), para analizar situaciones y manifestaciones culturales que perfila una antropología del ser humano capaz de experimentar el dolor no sólo corporal (por efectos de enfermedad, herida, castigo físico, tortura, parto, piedad o devoción, etc.), sino también espiritual, moral, afectivo, psicológico; ese es el caso del "enamorado doliente" (Saguar García, A., 2014, p. 1017), o el "siervo sufriente de Is 53, 4-8:

Este nuestros pecados lleva, y de nosotros duélese; y nosotros pensamos que él estaba en trabajo, y en plaga, y en maltratamiento. Pero él fue herido por nuestros pecados, y enfermo está por nuestras iniquidades; enseñanza (e) 
de paz nuestra sobre él; con el cardenal de él nosotros fuimos sanos. Todos, como ovejas, hemos errado; el hombre en su camino erró; y el Señor le entregó a nuestros pecados. Y él, con estar maltratado, no abre la boca; como oveja a matanza, es llevado; y como cordero ante el que trasquila, mudo, así no abre su boca. En la humillación su juicio fue quitado: - la generación de él ¿quién contará (f)? - porque es quitada de la tierra su vida; por las iniquidades de mi pueblo fue llevado a la muerte ${ }^{2}$.

El dolor físico y espiritual puede ser inconcebible a la vista de una persona desprevenida, sin embargo, el siervo lo soporta por donación absoluta, porque es su deber como siervo, no protesta, no reclama derechos, porque su vida no le pertenece, porque su naturaleza es servir. Jesús, del nuevo Testamento, encarna la característica del siervo sufriente del profeta Isaías. El Hijo de Dios lo sufre todo por todos como un auténtico siervo; siendo hijo de Dios ha asumido la condición más baja del status social para levantar al pequeño y para que los importantes y señores de la tierra se inclinen ante su pequeñez.

\section{La tortura, el suplicio y el heroísmo}

La sofisticación del tormento, del suplicio durante la vigencia de la "Santa Inquisición" alcanzó los niveles sobrehumanos, únicamente superados por la calamidad nazi. Lorenzo Gonzales, el último judaizante quemado vivo en 1719, quien fue apresado junto a su familia en 1713 mientras intentaba ponerse a buen recaudo manteniendo su fe mosaica o judía en desmedro de la fe católica es un digno representante de la tolerancia al dolor físico causado por las torturas; sobrellevó la soledad, el hambre, el vacío espiritual hasta morir en la hoguera. El mecanismo por el cual el tribunal inquisitorial lograba doblegar la voluntad y la convicción de personas libres era mediante el largo y fatigoso interrogatorio, amenazas, vejámenes, para culminar con la tortura y la sentencia de muerte (Marcos, M., 2010).

Historias como las que se han mencionado pululan a lo largo de la época medieval hasta finales del siglo XVI. El ensañamiento de los inquisidores hacia los herejes llegó a tal punto que realizaban exhumaciones para dictar

2 Jünemann Beckschaefer, Guillermo (1992), La Sagrada Biblia, Versión de la Septuaginta al español. Versión directa del griego, hebreo y arameo. Según los mejores códices: Vaticano, Sinaítico, Alejandrino y sus mejores ediciones. Texto bíblico autorizado para su publicación por la Conferencia Episcopal de Chile mediante el decreto n. 70 (860/92) con fecha del 8 de octubre de 1992. Documento electrónico de distribución gratuita preparado por VE Multimedios (www.vemultimedios.org) como un servicio a la Iglesia. 
sentencia post mortem y condenarlos a la hoguera a vista de familiares, amigos y pueblo en general como advertencia contra los herejes.

La condición de la mujer en todas las épocas históricas ha sido deprimente, de manera más intensa en el medievo donde fueron perseguidas y quemadas en la hoguera acusadas de sedición y brujería por el solo hecho de pensar por sí mismas y negarse a soportar las afrentas del machismo propio de una cultura elitista. Se argumentaba que la mujer era un ser inferior, incapaz de pensar por sí misma, vulnerable, proclive a la sensualidad, a la tentación y al pecado. Por lo que debía ser controlada con rigor para evitar la difusión masiva del mal.

A inicios del Renacimiento, se registra un elemento novedoso: la "ley de pernada" (ius primae noctis), el derecho sexual de la primera noche por parte del noble, del cura, sobre la mujer que contrae matrimonio. Esta ley se fundamentaba en el mito relacionado con el pecado y la sangre. Una mujer al ser desflorada, durante su primer acto sexual, derramaba sangre desatando un ataque masivo del mal; un ser humano espiritual, santo y fuerte debía controlar. La persona capacitada espiritualmente para enfrentar este fenómeno maléfico debía ser un sacerdote (chamán), el padre o la madre, el noble (Rucquoi, A., 1978).

Esto es un indicador de una sociedad excluyente donde la mujer no tenía ningún derecho. Las mujeres podían ser violadas por cualquier hombre, si eran viudas su condenación era la miseria, el abuso; las brujas debían morir torturadas, desnudas y quemadas; casi la totalidad de la población femenina era analfabeta, la mujer solo debía servir a su marido, al amo, al patrón y estaba obligada a parir hijos; a la mujer adúltera el marido podía matarla, a cambio recibía un castigo en proporción a la edad de la mujer: si era menor de 14 años, recibía la mitad de condena en prisión en equivalencia a un hombre asesinado, si su edad fluctuaba entre 14 y 20 años, la condena se reducía a una cuarta parte de tiempo y si la edad de la mujer era superior a los 20 años, el asesino no recibía ninguna sanción. Estas consideraciones se hacían por la fertilidad femenina; mientras más joven era una mujer su valor se incrementaba.

En las sociedades contemporáneas aún persisten estas costumbres bárbaras. Por ejemplo, en la cultura magrebí una mujer en la noche de bodas debe ser desflorada por la suegra con el filo de un puñal, si no conserva su virginidad debe morir en ese instante. ${ }^{3}$

3 Comentario recogido de los diálogos con Mohamad y Bahdría, durante los años en que trabajé en un Restaurante "Can Majó”, Barcelona-España (2000-2006). 
De lo expuesto se infiere que el dolor infringido en el cuerpo es el símbolo del poder y del dominio de unos pocos; controlar la conciencia, la libertad de expresión y de pensamiento, la profesión de fe, la economía, las relaciones sociales era el fin último de la "Santa Inquisición" con todo el aparato de poder. Fernando el Católico e Isabel la Católica se conoce que emprendieron la lucha contra los judaizantes (considerados herejes) con el propósito de apoderarse de sus pertenecías; los judíos fueron los que monopolizaban la riqueza, el dinero, la banca, los comercios durante la Edad Media.

El holocausto nazi es el prototipo de la degradación humana. Todas y cada una de las acciones que realizaban (torturas, hambre, frío, trabajos forzados, fatigas, desnutrición, enfermedades, aislamiento, etc.) perseguían un solo fin: aniquilar todo indicio de judaísmo. El dolor provocado por los alemanes en el cuerpo, en la mente y el espíritu de los judíos fue plenamente planificado, se utilizó una tecnología calculada del suplicio para comprobar los niveles de resistencia humana al dolor. Evidentemente, lo que deja entrever es el "afán de poder, el individualismo, el clasismo, la burocratización, la masificación y la xenofobia" (Prat, I. P. R., 2009, p. 13).

De cara a los dogmas católicos o a los principios hitlerianos se podría afirmar que sus procedimientos estaban justificados: eliminar herejes para fomentar "la sana doctrina católica"; limpiar la raza aria de la contaminación judía, del voraz enriquecimiento judío y su consecuente incremento poblacional. La propuesta nietzscheana de la exaltación de los valores dionisiacos o la trasmutación de los valores: asumir los valores cristianos como antivalores de la cultura occidental podría ser una alternativa a la renovación mental de occidente para el advenimiento del superhombre. Sin embargo, lo único que muestra este embarazoso conjunto de abusos y atentados a la vida es una iglesia institución actuando como simple instrumento de poder; se vislumbra un reducido grupo humano imponiendo su voluntad sobre el conglomerado humano universal y el creciente incremento irracional de grupos fundamentalistas ya sea de sesgo religioso, político o cultural.

El poder de un grupo selecto de la humanidad, la ambición desmesurada e incontrolable, el afán monopolizador de las mentes más retorcidas conducen a que personas libres, con pensamiento crítico y corazón puro se opongan decididamente hasta con su propia vida. Este hecho genera un valor heroico: entregar la vida por la causa de la justicia, por los que sufren, por los que lloran, por los pequeños, por los más vulnerables de la sociedad; el héroe es aquel que entrega la vida por los demás, por una causa humanizante, 
hace más de lo que los demás esperan de él (León, A. A., 2005). Jesús de Nazaret expresa el canto a la vida y a la libertad de una manera muy típica:

...Bienaventurados los pobres de espíritu, porque de ellos es el Reino de los Cielos.

Bienaventurados $=\operatorname{los}$ mansos $=$, porque $=$ ellos poseerán en herencia la tierra. Bienaventurados los que lloran, porque ellos serán consolados.

Bienaventurados los que tienen hambre y sed de la justicia, porque ellos serán saciados.

Bienaventurados los misericordiosos, porque ellos alcanzarán misericordia. Bienaventurados los limpios de corazón, porque ellos verán a Dios.

Bienaventurados los que trabajan por la paz, porque ellos serán llamados hijos de Dios.

Bienaventurados los perseguidos por causa de la justicia, porque de ellos es el Reino de los Cielos.

Bienaventurados seréis cuando os injurien, y os persigan y digan con mentira toda clase de mal contra vosotros por mi causa.

Alegraos y regocijaos, porque vuestra recompensa será grande en los cielos; pues de la misma manera persiguieron a los profetas anteriores a vosotros.

«Vosotros sois la sal de la tierra. Mas si la sal se desvirtúa, ¿con qué se la salará? Ya no sirve para nada más que para ser tirada afuera y pisoteada por los hombres.

«Vosotros sois la luz del mundo. No puede ocultarse una ciudad situada en la cima de un monte. Ni tampoco se enciende una lámpara y la ponen debajo del celemín, sino sobre el candelero, para que alumbre a todos los que están en la casa. Brille así vuestra luz delante de los hombres, para que vean vuestras buenas obras y glorifiquen a vuestro Padre que está en los cielos (de Jerusalén, B., 1998) ${ }^{4}$.

Evidentemente la comprensión del cuerpo se entiende en un contexto de la "microfísica del poder" al estilo foucaultiano; poder y dominio son almas gemelas que se materializan en la corporeidad del ser humano, en sus diversas manifestaciones fácticas (Uribe, A. A. B., 2006).

Las mafias en América Latina, los grupos reaccionarios, el paramilitarismo, el sicarito son formas de violencia que han generado un cierto tipo de pedagogía cultural; los hijos, los familiares, los seres queridos de todas y cada una de las víctimas deben aprender, deben registrar en su memoria, en base a

4 Mt 5, 1-16. 
las muertes violentas de sus difuntos las consecuencias que les devienen si no se ajustan a las demandas del poder y del dominio. El terror es la tecnología mediante la cual someten a sus víctimas, construyen una simbología fácil de asimilar y olvidar.

Los cuerpos de las víctimas en sí mismos son símbolos de dominio. Cada marca, cada golpe, cada gota de sangre derramada, cada miembro amputado debe impregnar en la consciencia de los que se quedan un recuerdo de la obediencia y sumisión que hay que tributar al victimario.

Los delincuentes ${ }^{5}$ deben brindar un trato cruel, sanguinario con el propósito de que la víctima desobediente no vuelva, no retorne. Las víctimas inician un camino, en el suplicio y la tortura, sin retorno. Son los que han partido y no volverán. Los que se quedan han aprendido la lección.

La antropología de la violencia va tomando forma en la medida en que vamos realizando una lectura atenta, minuciosa de los nuevos símbolos de dominio, de las nuevas formas de delinquir y deshumanizar el planeta, aplicada por los diversos sujetos denominados delincuentes. Las políticas de estado no hacen sino jugar al gato y al ratón, multiplican la violencia, el terror. Si el victimario ha incurrido en una de sus acciones tétricas, el poder de la justicia aplica todo el peso de la ley sobre esos cuerpos, condenando a las penas máximas (en los 31 estados de los Estados Unidos de Norte América: la pena de muerte). A los políticos no les interesa discutir sobre este tema trascendental y vital para la humanidad. Hay que callar, encerrar, castigar y vengarse de todos aquellos antisociales, victimarios.

Entre las alternativas para superar esta cadena de violencia y terror, de poder y dominio está una educación que abarque dos frentes: el conocimiento y los valores ¿Qué valores? Aquellos que hacen del ser humano un ser cada vez más humano, sensible con la vida, condescendiente con sus congéneres.

\section{La cultura del dolor y el sacrificio}

El ser humano ha encontrado un sentido al dolor físico; se puede sufrir, se puede padecer porque se puede alcanzar el cielo, la eternidad, el paraíso, el más allá luego de la muerte. En ello radica el sacrificio, en volver lo coti-

5 Personas que se juzgan incapaces de ejecutar un esquema de acción que les lleve al éxito, por lo tanto, se ven abocados a cometer actos inmorales, delictivos o simplemente problemáticos (Garrido, M. E., Masip, P. J., \& Herrero, A. C., 2009). 
diano (el dolor, el sufrimiento) en un oficio sagrado en la vida, sin rechazarlo. Este fue el argumento que por milenios ha gobernado la consciencia del hombre y del que se han servido unos cuantos "vivos" (oportunistas, caprichosos, egoístas y rufianes) para esclavizar a sus hermanos.

Hacia mediados del segundo milenio a.C., las tribus hebreas expresaban su identidad respecto de las demás tribus por la circuncisión. Indudablemente este acto ocasionaría dolor en los infantes y en los individuos ajenos a la tribu que pretendían integrarse al clan familiar. La circuncisión se imponía como condición única para que una persona sea aceptada, en la mencionada tribu, con fines conyugales, si el pretendiente pertenecía a tribus foráneas. De este condicionante se valieron los hermanos de una adolescente violada por una tribu vecina. Acordaron lo siguiente: para que su hermana no quedara en deshonra, el agresor, junto con su familia, debía circuncidarse, luego de lo cual se realizaría la ceremonia nupcial al estilo de la tribu hebrea. Lógicamente los hombres tuvieron que aceptar esta regla. Cuando todos estaban adoloridos, reposando, los hebreos ofendidos pasaron a cuchillo a todos quienes no podían defenderse por su condición dolorosa por la que atravesaban.

Los grupos tribales de la media luna fértil se distinguían de los demás por sus costumbres, por su manera de hacer frente al dolor; en Babilonia el tratamiento que se otorgaba a las enfermedades y al dolor físico lo proporcionaba un sacerdote, debido a que el dolor corporal estaba íntimamente relacionado con los padecimientos espirituales experimentados por las personas, algo similar a la costumbre Inca en Sudamérica. El sacerdote debía aplacar la ira de los dioses. Los egipcios, por su parte, consideraban que las enfermedades y el dolor eran causadas por algún espíritu nocivo, que se introducía en el cuerpo mediante diferentes vías y se podía expulsar por la orina, el estornudo o el sudor. En la India se asume al dolor como fruto de las frustraciones y la única manera de eliminarlo es mediante el rechazo de los deseos (Torres y Compañ, 2006, p. 7).

En las culturas andinas, precolombinas, la identidad de las personas que pertenecían a la jerarquía se expresaba por grandes perforaciones e incrustaciones exóticas en diferentes partes de su cuerpo. Por ejemplo, los Incas se perforaban las orejas y se incrustaban anillos lo suficientemente grandes, a tal punto que las culturas y civilizaciones por ellos conquistadas les otorgaron el calificativo de orejones. Las enfermedades se consideraban un castigo divino por los actos malévolos cometidos; las personas autorizadas para 
brindar un tratamiento eran los sacerdotes mediante la magia, las oraciones, el ayuno, sacrificios de diversa índole y el empleo de la medicina natural.

Los incas practicaban sacrificios humanos al espíritu de las montañas, ascendían a los nevados más altos y ofrecían infantes a la divinidad. Los dejaban congelarse, luego de masticar la coca para aliviar el dolor provocado por el frío intenso. Practicaban cirugías craneales cuando el paciente había sufrido una fractura como producto de un impacto de proyectiles (trozos de rocas redondeadas) disparadas utilizando la honda ("huaraca"6) o provocadas por el impacto de mazos, hachas y boleadoras aprovechando el estado de inconsciencia del herido; extraían el fragmento de hueso estropeado sin tocar la masa encefálica, con el fin de evitar hemorragias craneales o acumulación de líquidos, con lo que conseguían salvar cientos de vidas. Era una civilización que manejaba muy bien el impacto del dolor corporal como instrumento para forjar el carácter, la obediencia y disciplina; herencia precolombina es la "justicia indígena"7 vigente hasta la actualidad en el sector indígena y campesino del Ecuador.

En lo referente al sacrificio corporal y espiritual se presenta algunos ejemplos de experiencias vividas por los ecuatorianos con mezcla de folklor, religiosidad y rezagos de dominación colonial. En las tres celebraciones ecuatorianas importantes de tipo religioso, en tiempos diferentes y estratégicos del año lectivo (El Señor del Gran Poder en Semana Santa: Viernes Santo; la festividad de la Virgen del Cisne, 15 de agosto, y la de la Virgen del Quinche, 21 de noviembre) los fieles y peregrinos comentan que la "devoción" les permite realizar grandes caminatas a pie descalzo, de rodillas, sin agua, bajo un recalcitrante sol o la lluvia y el gélido frío. Estas acciones

6 Cuerda de $3 \mathrm{~m}$ de longitud, en el centro se colocaba el proyectil, una roca redonda (de un peso aproximado de $1 / 4$ de libra) que era disparada por efecto de la fuerza centrífuga. Pertenecía al grupo de las armas ofensivas.

7 Los moradores de los sectores campesinos e indígenas reunidos en asamblea deciden imponer un castigo físico a los individuos que han alterado el "sumak kausay" (buen vivir). El procedimiento es el siguiente: la asamblea en pleno, luego de todas las averiguaciones realizadas, una vez comprobado el delito aplica el castigo que consiste en un baño con agua helada para expulsar los malos espíritus; luego de azotarles con maytus (envolturas) de ortiga para provocar remordimiento de consciencia se cierra el ceremonial con unos cuantos latigazos (cuerdas retorcidas y resecas realizadas con cuero de res) con la finalidad de fijar en la mente, en el cuerpo y el corazón del delincuente la fidelidad a las buenas costumbres que impactan en la construcción de armonía social. El dolor corporal ejerce dominio a nivel de la consciencia del malhechor provocando una suerte de rehabilitación física, psicológica y espiritual. Los ancianos y las autoridades de la comunidad son los que aplican el castigo al tiempo que recriminan verbalmente y aconsejan el ejercicio de un modo de vida pleno. 
constituyen una penitencia suplicando a la divinidad el perdón de los pecados cometidos, el milagro esperado, la curación a sus males, la fortaleza para superar sus heridas espirituales, la unidad familiar, la consecución de un negocio o la llegada a un país extranjero con miras a mejorar su economía, etc.

El inmenso bagaje de formas y manifestaciones religioso-culturales están matizadas por patrones de dominación y de conquista, tanto si se trata de las culturas precolombinas, coloniales o postcoloniales. El ser humano, por naturaleza, busca una razón vital fuera de sí, espera una respuesta favorable del objeto de su adoración (Rodríguez-Shadow, María, y Ávila, Ricardo, 2010). En esta búsqueda constante de motivos para sobreponerse al hambre, al cansancio, al dolor físico experimentado por efectos del látigo del patrón, a la impotencia de presenciar a su cónyuge siendo violada por el patrón, etc., el indio tuvo que sublimar su sufrimiento para alcanzar la gloria, la paz y la alegría plena en el paraíso, en la otra vida. En esta coyuntura el "cura" significó un factor crucial, en el proceso de la conquista, mediante la fe en Cristo sufriente, en la cruz del dolor y la muerte, cerró el círculo de poder y dominio en nombre de Dios y del Cristo que trajeron:

Y entre Curas, tam, unos pareciendo, buitres, diablos, había.

Iguales. Peores que los de dos piernas.

Otros decían: "Hijo, amor a Cristo".

unos decían: "Contribución, mitayo, a trabajar en mi hacienda,

a tejer dentro de iglesia,

cera para monumento, aceite para lámpara,

huevos de ceniza, doctrina y ciegos doctrineros ${ }^{8}$.

El dolor físico, el sufrimiento, la tristeza pasaron a formar parte fundamental de la existencia del indio, del pobre, del conquistado, del mitayo. Enseñaron que Dios ve con buenos ojos al pobre, al pequeño, al indio porque sabe sufrir; la vida era sinónimo de sufrimiento y dolor, la felicidad se alcanzaba en la eternidad siempre que se cumplía con los parámetros exigidos por el patrón. El dios, objeto de la piedad popular ecuatoriana (latinoameri-

8 César Dávila Andrade, Boletín y Elegía de las Mitas, Pachacamac http://pacoweb.net/Cantatas/Boletin.htm 
cana), adquirió un rostro del rey todo poderoso, vengativo, castigador y, de vez en cuando, benévolo. Así que para agradar y alcanzar sus promesas de eternidad y salvación hay que realizar sacrificios corporales, peregrinaciones, romerías.

Hoy, el ecuatoriano, aunque no vive los efectos tormentosos de la esclavitud colonial, su mentalidad continúa reproduciendo la simbología de dominio, opresión y poder en sus prácticas religiosas cotidianas. No hay que olvidar que el dominio ideológico es el de más larga duración en la historia de la humanidad. Desde esta experiencia se puede entender la majestuosidad de los templos de mayor peregrinación anual tales como: El Cisne en la provincia de Loja; El Quinche en Quito capital del Ecuador; La Nube en la ciudad de Azogues de la provincia del Cañar; El Rocío en el cantón Biblián; Las Lajas en el municipio de Ipiales (Departamento de Nariño, sur de Colombia), etc. El dios todopoderoso debe habitar en templos majestuosos, imponentes, dignos de su señorío ${ }^{9}$.

Sin duda alguna, la Virgen María vería con buenos ojos a sus hijos peregrinando hasta su santuario, clamando su misericordia; cuantos más sacrificios corporales realicen sus hijos, la Madre bendita se sentiría dichosa y cumpliría con los milagros esperados, por ser la madre del "dios todopoderoso"

En un viaje al Cisne realizado el 10 de mayo del 2015, por motivos de estudio etnográfico, en un tramo de la carretera "E 35 " de unos 25 kilómetros, tuve la oportunidad de presenciar a cientos de peregrinos, mientras ascendía al santuario en mención: unos caminaban descalzos, otros se apoyaban en muletas, otros empujaban coches de niños y en sus espaldas cargaban pesadas maletas. En algunos puntos me detuve a conversar con los peregrinos, generalmente eran personas que padecía enfermedades catastróficas o se preparaban para cruzar la frontera México-Estados Unidos, otros iban a cumplir su promesa por una bendición o un milagro recibidos. El 100\% de la población entrevistada argumentaba que realizaban ese sacrificio por fe y devoción.

La devoción ${ }^{10}$, es un indicador esencial de la unidad de la existencia del ser humano latinoamericano con su creador, siendo éste infinitamente superior, todopoderoso, severo con el pecador. El hijo miserable, pecador, digno

9 Si el Rey habita en un castillo, el emperador en su palacio, también el Señor Dios debe habitar en un templo majestuoso, pomposo, imponente desde donde administra su poder y gloria.

10 Debo adoración, del verbo deber algo a alguien, la deuda hay que pagarla. 
de condenación debe realizar cuantos sacrificios físicos sean necesarios para alcanzar el perdón o por lo menos un favor del "señor dios".

\section{El concepto del cuerpo en diversos escenarios históricos}

En la Grecia arcaica no hay una clara distinción entre cuerpo y alma, entre lo natural y sobrenatural. "Así, la realidad corporal del hombre incluía los aspectos orgánicos, las fuerzas vitales, las actividades físicas, las aspiraciones y los influjos divinos". (Duch, L., \& Mèlich, J., 2012, p. 36). Federico Nietzsche en su propuesta sobre advenimiento del superhombre acoge con radicalidad esta postura de la Grecia vetusta, cosa que ya los renacentistas italianos habían iniciado hacia finales del siglo XIV e inicios del XV. La corporeidad humana, en la concepción griega, a diferencia de los dioses (los que existen eternamente) es efímera. Sin embargo, los griegos no solo que representaban a los dioses a imagen humana, sino que tuvieron la firme convicción de que un cuerpo, sobre todo joven, trasparentaba la divinidad en toda su luminosidad, fuerza, belleza y juventud eterna.

En la Grecia de los siglos V y IV a.e.c. surgen ya representaciones del cuerpo de manera dual (cuerpo-alma) en estrecha relación con los conceptos de microcosmos y macrocosmos.

En el contexto bíblico, a diferencia de los griegos, el cuerpo representa una completa unidad orgánica, aunque en la tradición yahvista de la creación el cuerpo se diferencia del principio vital. San Pablo (en la Carta a los romanos) por primera vez adopta los conceptos de cuerpo de pecado o cuerpo mortal (carne) y Cuerpo de Cristo; el hombre mientras sigue sus criterios puramente humanos y egolátricos, en un momento dado se verá abocado a un laberinto de sufrimientos, angustias, traumas y fracasos. Mientras que por la fe en Cristo, el hombre es libre para amar, libre para vivir al estilo de Cristo, como verdadero hijo de Dios.

La Iglesia católica medieval ha creado una cultura adversa con respecto al cuerpo, considerándolo pecaminoso y detestable. Una era medieval de corte agustiniana que priorizó el alma respecto del cuerpo, construyó su propia teología fundamentada en las categorías de la filosofía platónica; la teoría del alma y cuerpo: dos componentes antagónicos del ser humano. El alma pertenece al mundo de las ideas, al reino celestial; habiéndose contaminado por su contacto con el cuerpo debía purificarse pasando por el estado del purgatorio antes de llegar definitivamente al reino Celestial. Lógica- 
mente un alma perversa debía pasar definitivamente al reino de las tinieblas o infierno. El cuerpo es esencialmente corrupto, temporal y perecedero, por lo que un alma que había estado en contacto con él inevitablemente debía ser corrupta e impura, había que limpiar o purgar el mal. Este fue el fundamento ideológico que sirvió de sustento teórico para la creación y difusión de la doctrina de las indulgencias y la "Santa Inquisición", símbolos todos del poder, dominio y violencia.

En el siglo V (según el criterio del historiador Lactancio solo la Iglesia conserva y sostiene todo) se establecen la mayor cantidad de dogmas católicos, se afianza la ortodoxia doctrinal y se consolidan las herejías (monofisismo, nestorianismo pelagianismo). San Agustín aparece en este andamiaje histórico con su elaborada teología del pecado basado en la contaminación del alma por su contacto con el cuerpo. El cuerpo capaz de sentir placer y dolor no es el objeto adecuado para la morada del alma. Este fue el inicio de la construcción de un nuevo concepto adjunto al purgatorio: el infierno (lugar de lamento eterno de las almas perdidas, contaminadas por la concupiscencia). De alguna manera durante toda la Edad Media se vinculó la imagen del cuerpo con el sexo, con el placer, el goce y el deleite mundano, desde todo punto de vista ajeno a los propósitos del Evangelio de Jesús.

Santa Teresa de Jesús en su obra "Las Moradas" diseña una forma de entender el cuerpo humano compuesto de cuerpo y alma. Si el cuerpo corresponde a la representación de un castillo, el alma viene a ser el soberano del castillo. Indudablemente el castillo, por un descuido del soberano se llena de alimañas, maleza y toda clase de objetos destructivos. De esto se desprende la razón por la cual el ser humano en su vida cotidiana debe privar a su cuerpo de toda clase de vicios a fin de que el alma no se inquiete y contamine. Santa teresa denomina al cuerpo hombre exterior y al alma hombre interior. Este criterio sigue la línea tradicional del medievo de dominio de la razón y la fe sobre la carne. El cuerpo estuvo relegado a la ideología religiosa de los diez siglos del Medievo (Santa, T. D. J., 2004).

En las culturas latinoamericanas, el cuerpo es una expresión de identidad con la naturaleza y la fuente de las relaciones interpersonales tanto con el otro ser humano como con la divinidad. Por ejemplo, los pueblos y nacionalidades amazónicas, los Taromenane, Tagaeri, Zapara, Shuar, etc., expresan en su cuerpo su identidad con la naturaleza, por lo que sus tatuajes son vivencia de los arquetipos culturales. Federico González Suárez en su Obra Estudio histórico de los Cañaris (grupo cultural precolombino de Sudamé- 
rica, ubicado en el austro ecuatoriano), recoge testimonio de los conquistadores quienes afirman que son grupos culturales en cuyos cuerpos y rostros representan tatuajes de manera exagerada, a menudo se recargan de objetos en distintas partes de sus cuerpos con perforaciones (González, 1989).

El concepto de cuerpo que manejan las culturas latinoamericanas difiere considerablemente de la mentalidad occidental-europea. Si en concepción europea del medievo el cuerpo fue el caldo de cultivo de todos los males y perversiones del género humano y, por ende, debía someterse a suplicio ${ }^{11}$, en la mentalidad andina el cuerpo es una totalidad; es el punto de partida y de llegada de todas las dimensiones de la existencia humana: hawa pacha, kay pacha, uku pacha ${ }^{12}$.

El hombre moderno expresa en su cuerpo una frontera de su yo (individual, egoísta). Su cuerpo es el inicio y fin del universo existencial, nadie puede invadir ese santuario egocéntrico, absorbe en dirección centrípeta todas las ventajas de la realidad práctica; es un agujero negro en el espacio individual. Ninguna energía debe desperdiciarse en dirección al otro: todo para sí; YO-YO-YO. Esta falencia cultural debe superarse mediante un cambio de mentalidad a nivel universal.

\section{El cuerpo, la enfermedad y el mercado}

El hombre postmoderno evita el dolor físico, el sufrimiento, a cambio busca la felicidad, aunque ésta última la confunda con el placer, el hedonismo en todas sus manifestaciones existenciales. Si el fin último de su existencia es la experiencia del placer, la utilidad que la persona pueda conseguir de cada uno de sus actos, del bienestar corporal, entonces, el dolor y el sufrimiento serán descartados de su canon de vida, a menos que el dolor y el sufrimiento provocados a otras personas sirvan como instrumentos de dominio y poder.

En estos principios se fundamenta una civilización transitoria y volátil, el relativismo ético en su máxima degradación, donde los valores sólo se viven según las circunstancias, los momentos; para esta generación la infor-

11 En el interior de las órdenes religiosas se practicaba la disciplina: castigo corporal que se debía ejecutar por regla.

12 hawa pacha (mundo de los espíritus), kay pacha (mundo de los vivos), $u k u$ pacha (mundo de los difuntos; no es lo mismo que mundo de los muertos). Los que pertenecen al tercer mundo no están muertos, han pasado a otro estado de existencia, con quienes los vivos deben mantener una relación espiritual, visiblemente expresada en sus diversas manifestaciones religioso-culturales. 
mación y la identidad son reciclables: el ser humano adopta una actitud camaleónica siendo lo que el entorno pide de él (Vásquez, R. A., 2010).

Según estos criterios, los enfermos, los sufrientes deben ser excluidos, encerrados, rechazados y aniquilados, la utilidad que se pueda obtener de esta inmensa mayoría de la población es negativa, no hay espacio para la "felicidad-placer"; cada uno busca su cubículo existencial construido, fabricado a su medida, el otro no tiene lugar en ese micro-universo, donde el yo-todo, es uno sólo. La generación de este milenio tiene una discapacidad innata: ¡No puede pensar en el otro ser humano, sino en sí mismo!

El mercado farmacéutico, la industria cosmetológica salen al encuentro de un ser sin una determinada identidad, cuya corporeidad debe ajustarse a la medida del aquí y el ahora. Si el ser humano rechaza el dolor, el sufrimiento, la angustia, le interesa la utilidad y el placer, entonces entra en un proceso vicioso del consumismo; la oferta de productos "beneficiosos para la salud", cosméticos para mejorar la apariencia física, a fin de conseguir una aceptación social eminentemente narcisista son los medios que moldean al hombre postmoderno-egoísta-utilitario-hedonista.

El Plan Nacional de Desarrollo del Ecuador contiene 12 Objetivos Nacionales, de los cuales el Objetivo 3 se refiere a mejorar la calidad de vida de la población, donde la salud es el fundamento para alcanzar esa mejora (Quezada, A., 2011, p. 1).

Según la política del Estado ecuatoriano la calidad de vida se mide por la salud de la población, para ello ha destinado US\$2 492000 para el año 2015 de un total de US\$36 $317000^{13}$ del presupuesto nacional, es decir un 6\%.

Si se analiza el mercado farmacéutico ecuatoriano se verá lo siguiente: los productos farmacéuticos de prescripción médica abarcan un total del 85\%, solo el 15\% son de venta libre. Hace 30 años el uso de los productos genéricos ascendía al 3\% utilizado por la población. Para el 2011 únicamente se ha incrementado al $6.5 \%$ de esa demanda. Este indicador muestra que la población busca la marca, no solamente en los medicamentos sino en todos los productos de uso masivo, aunque la utilidad y los beneficios sean los mismos.

La población ecuatoriana mayoritariamente dependiente de los servicios de salud pública y del hospital del IESS no confía en los productos genéricos

13 Cifras obtenidas de la página oficial del gobierno nacional ecuatoriano: http://www.elciudadano. gob.ec/los-sectores-estrategicos-prioridad-en-el-presupuesto-del-2015/ 
y escasos en cuanto a variedad. Aunque la salud es gratuita y la atención en los centros y sub-centros de salud pública evidencia incrementos en la eficiencia y eficacia con relación a los períodos de gobierno anteriores al 2007, la burocracia y la tramitología restan credibilidad a esta política de gobierno. El mercado farmacéutico de uso y distribución entre la población ecuatoriana dependiente de la salud pública solo cubre el 6.5\%. El 94.5\% de los productos son de patentes internacionales, de costos elevados, pero que, según el criterio de la población causan mejores efectos en la salud.

Un afiliado al IESS puede ser atendido previa una cita telefónica y tarda entre 3 y 5 días, en medicina general o familiar. Mientras que la atención especializada se administra por solicitud del médico familiar o general, lo que implica un largo trámite burocrático y una espera tediosa entre 1 y 3 meses, incluso la espera puede extenderse hasta los 6 meses. Por lo que los afiliados al IESS prefieren acudir a los hospitales y clínicas particulares. El ministerio de salud ha firmado convenios con algunas entidades privadas (clínicas y hospitales) para brindar una mejor atención a la ciudadanía, no se ha mejorado la atención, sino que se ha camuflado en un enrevesado proceso burocrático.

En esta dinámica el negocio de la medicina, continúa su crecimiento. El estado ecuatoriano fortalece al negocio privado de la medicina, porque contrata médicos de las clínicas particulares y consultorios particulares, además el suministro de los medicamentos sigue en manos privadas.

Para el negocio de la medicina que, para intereses comerciales, confunde con el concepto salud, mientras más enfermos haya mayor es el incremento de su capital. Contrariamente, para la sociedad cuando tiene frente a sí una persona enferma prevé gastos, supone incomodidades, una carga familiar; el enfermo debe curarse, aunque a costos elevados; un individuo que se considere feo, que se sienta rechazado por la sociedad se ve abocado a realizar diversas acciones para superar esas anomalías. Entonces recurre a los medicamentos costosos, de marca, a los cosméticos, a las cirugías estéticas de elevados costos. Por lo que la industria farmacológica y cosmetológica resulta un negocio con alta rentabilidad en países como Ecuador, donde supuestamente la salud es gratuita.

\section{El cuerpo y su dimensión relacional saludable}

Hay que entender que el cuerpo es la fuente de viva manifestación de la personalidad. El cuerpo es la dimensión social-relacional del ser humano. Lo 
que ES se expresa por su cuerpo. A menudo se afirma es negro, blanco, pequeños, gordo, tranquilo, grosero, gruñón, espiritual, tierno, romántico, etc. Todo lo que el OTRO puede asumir y captar del YO se realiza por la expresividad simbólica del cuerpo. No hay una razón suficiente por la que debamos hablar del ser humano reducido al puro espiritualismo (Edad Media) o al materialismo (modernidad y postmodernidad); tampoco se puede generalizar el concepto de cultura líquida (no consistente). Hay que entender al ser humano en su corporeidad inmerso en un contexto, con una historia, heredero de una cultura, de un potencial evolutivo. El ser humano es una totalidad: es ser humano.

De la misma manera que una persona no puede aislar el dolor provocado por un corte en uno de los dedos de su mano, sino que sufre en su totalidad, resulta imposible fragmentar la estructura totalizante de ser humano. El concepto cuerpo involucra a la persona en su totalidad. La angustia, el stress, el coraje, el disgusto, la alegría, la felicidad, la enfermedad, el dolor que padece la persona se manifiesta y es visible gracias al cuerpo. Por ello los psicólogos hablan de la somatización de los problemas psíquicos. Cuando se refiere por ejemplo a la gastritis y las gastropatías la revista de Gastroenterología del Perú afirma que "las causas más comunes de gastritis y gastropatías agudas son el Helicobacter pylori, las lesiones mucosas por estrés y los AINES (antiinflamatorios no esteroideos)", es decir, los estados de ánimo impactan en la salud corporal y en su apariencia relacional (Valdivia Roldán, M., 2011, p. 39).

Cuando se trata la problemática del cuerpo y el dolor, sin duda alguna se refiere al ser humano en su estado relacional-simbólico, en su proceso de construcción o de-construcción social, en su experiencia vívida de la realidad. El cuerpo del ser humano es una unidad total que se expresa, se comunica, se relaciona, hace historia, establece vínculos sociales y construye una cultura. Desde esta lógica, la persona solo tiene sentido en la medida en que es corporeidad situada en espacio y tiempo.

La arquitectura del mercado farmacéutico conoce a la perfección la vulnerabilidad del ser humano y su preocupación por mantener un cuerpo saludable; es importante la salud. En las culturas campesinas del Austro ecuatoriano, en especial en Cañar, cuando se encuentran dos personas de camino hacia un punto $\mathrm{X}$, se saludan ¡Buenos días! Entre ellos se entabla un diálogo y la pregunta que se plantea es: ¿cómo ha pasado? Uno de ellos responde ¡Con salud! Sin "salud”, dicen los campesinos, no hay alegría ni felicidad, no se puede realizar las actividades cotidianas con normalidad. La persona decae física y anímicamente, su energía positiva se convierte en negativa, lo 
cual es objeto de rechazo en la sociedad ecuatoriana. Una persona enferma, es objeto de máxima preocupación por parte de los familiares en las etapas iniciales, con el trascurso del tiempo se convierte en un fardo muy pesado.

El cuerpo, el símbolo social de relaciones interpersonales debe manifestar plenitud, tranquilidad, gozo, alegría, debe ser saludable, lo opuesto genera aislamiento social del individuo que lo padece. En este contexto brota una cultura del desecho, donde todo es objeto de reemplazo. El Papa Francisco diría que vivimos inmersos en la cultura del "descarte". El jubilado, el anciano, el enfermo, el ser humano con capacidades diferentes, la mujer embarazada, el indocto, los niños, los pobres serían las principales víctimas de esta cultura del "descarte". El sujeto se ha despojado de SER, de su onticidad, para adoptar el lugar del objeto utilizable, factible.

Hoy están de moda los centros gerontológicos y los hospicios para ancianos en el Ecuador porque la persona de tercera edad molesta, incomoda a la familia por sus constantes enfermedades, por su demencia senil, por su fragilidad física, porque ya no produce para la sociedad, etc. La salida fácil es el olvido en un albergue y la visita furtiva de sus allegados. Los ancianos no prometen nada en lo que a ingresos económicos se refiere. La justificación para alimentar la cultura utilitarista y de la exclusión es que una persona vieja debe estar bien atendida en un lugar donde hay vivienda, alimentación, medicina. Sin embargo nos hemos olvidado que el afecto de la familia, la cercanía, el calor del hogar son elementos que solidifican el espíritu humano.

La persona saludable genera bienestar, trabajo, son "útiles". Tal vez por estas razones se valora la salud física. A esta cultura de la eterna juventud (la útil, la ágil, la productiva, la excluyente) la industria farmacéutica y cosmetológica ofrece un amplio bagaje de productos para no envejecer, para estar saludables, para ser más productivos a pesar de los altos precios.

Por todas las circunstancias antes mencionadas urge construir una mentalidad y una cultura donde el ser humano sea valioso simplemente por su condición humana, digna. Hay que construir una cultura incluyente, donde las capacidades diferentes, especiales cuenten como hechos evidentes, donde la presencia del sujeto en la sociedad sea importante y crucial.

\section{El ser humano y la conquista del cuerpo}

La supuesta conquista del mundo y del universo ha eludido la conquista del cuerpo; se ha desplegado un inconmensurable bagaje de recursos a fin 
de hacer frente al dolor, obesidad, desnutrición, enfermedad. El hombre se angustia por la persistencia de enfermedades catastróficas tales como el cáncer o el VIH, la gripe, etc.; simultáneamente brotan nuevas y desconcertantes epidemias que azotan a los pueblos sumergidos en la pobreza (cultural, económica, espiritual, científica, energética y de proyectos sustentables).

El hombre no quiere padecer el dolor, no quiere sufrir, no está contento con su cuerpo; unos desean incrementar su peso, otros bajar de peso aunque tengan que destinar un alto porcentaje del presupuesto familiar al amoldamiento del cuerpo a los diversos gustos y caprichos. Un cuerpo feo es un instrumento de sumisión, de dominio por parte de quien lo observa.

Todas estas cavilaciones del hombre contemporáneo no son sino una búsqueda desesperada de identidad, status, dominio y poder. Gregg Braden, comenta que tenemos entre manos las innovaciones tecnológicas con capacidad para colocar al hombre en la luna; sin embargo, sufrimos, lloramos, nos angustiamos, hacemos daño a los demás y no entendemos cómo lo bueno que hacemos se nos devuelve con creces. Pero también el mal que hacemos nos golpea con fuerza. Cosechamos lo que sembramos.

Existe una energía universal de la cual todos dependemos, todo está conectado dentro de esa gran Matriz Divina, nuestras acciones y decisiones tienen un impacto social y universal.

Con seguridad el futuro del ser humano será de una progresiva integración de la consciencia, en la medida en que su cuerpo y su consciencia del mismo sean uno sólo.

\section{Conclusión}

El cuerpo, estructura única y fundamental de las relaciones socioculturales, unidad íntegra de la personalidad debe ser asimilado por la experiencia humana con autenticidad, sin abusos ni fundamentalismos que acrediten una cultura del dolor y resignación, tampoco una cultura del mercado que hagan del cuerpo un objeto mercantil, en desmedro de los valores éticos que sólo acrecientan la brecha entre ricos y pobres. Sin embargo, el ser humano debe cuidar de su cuerpo porque su personalidad se refleja social y culturalmente en él. 


\section{Bibliografía}

De Jerusalén, Biblia (1998). Nueva edición revisada y aumentada. Desclée de Brouwer, Bilbao.

Duch, L., \& Mèlich, J. (2012). Escenarios de la corporeidad. España: Editorial Trotta, S.A. Recuperado de http://www.ebrary.com

Garrido, M. E., Masip, P. J., \& Herrero, A. C. (2009). Autoeficacia y delincuencia. España: Dykinson. Recuperado de http://www.ebrary.com

González Suárez, Federico (1989). Estudio histórico de los Cañaris, Biblioteca ecuatoriana clásica. Quito, Ecuador.

Jünemann Beckschaefer, Guillermo (1992). La Sagrada Biblia, Versión de la septuaginta al español. Versión directa del griego, hebreo y arameo. Según los mejores códices: Vaticano, Sinaítico, Alejandrino y sus mejores ediciones. Texto bíblico autorizado para su publicación por la Conferencia Episcopal de Chile mediante el decreto n. 70 (860/92) con fecha del 8 de octubre de 1992. Documento electrónico de distribución gratuita preparado por VE Multimedios (www.vemultimedios.org) como un servicio a la Iglesia.

León, A. A. (2005). La condición de héroe. Chile: Red PHARO. Recuperado de http://www.ebrary.com

Marcos, M. (Ed.) (2010). Herejes en la historia. España: Editorial Trotta, S.A. Recuperado de http://www.ebrary.com

Martí, J., \& Martí, J. (2008). Los pueblos indígenas y la cultura del cuerpo. España: Editorial UOC. Recuperado de http://www.ebrary.com

Newiger, C., \& Beinborn, B. (2002). Osteopatía. Barcelona: Editorial Paidotribo.

Prat, I. P. R. (2009). Y les lavó los pies: una antropología según el Evangelio. España: Editorial Milenio. Recuperado de http://www.ebrary.com

Quezada, A. (2011). La industria farmacéutica en el Ecuador: mirando hacia adelante. Revista E+ E Espae y Empresa, 2.

Rodríguez-Shadow, María, \& Ávila, Ricardo (2010). Santuarios, peregrinaciones y religiosidad popular. México: Universidad de Guadalajara. ProQuest ebrary. Web. 18 June 2015.

Rucquoi, A. (1978). Historia de un tópico: la mujer en la Edad Media. Historia, 16 (21), 104-113.

Saguar García, A. (2014). ¿Cuál dolor puede ser tal / que se iguale con mi mal?: entre la poesía de cancionero y la intertextualidad bíblica. Bulletin of Hispanic Studies (1475-3839), 91(8), 1015-1024. 
Santa Teresa de Jesús (2004). Las moradas. Argentina: El Cid Editor. Recuperado de http://www.ebrary.com

Torres, M., \& Compañ, V. (2006). La experiencia del dolor. España: Editorial UOC. Recuperado de http://www.ebrary.com

Uribe, A. A. B. (2006). Notas sobre la representación del cuerpo en la obra de Michel Foucault. México: Red Estudios sobre las Culturas Contemporáneas. Recuperado de http://www.ebrary.com

Valdivia Roldán, M. (2011). Gastritis y gastropatías. Revista de Gastroenterología del Perú, 31(1), 38-48.

Vásquez, R. A. (2010). Zygmunt Bauman: modernidad líquida y fragilidad humana. Nómadas. Revista Crítica de Ciencias Sociales y Jurídicas, 19(3), 309316, 2008. España: Universidad Complutense de Madrid. Recuperado de http://www.ebrary.com

Fecha de recepción: 3/12/2015; fecha de aprobación: 1/4/2016 